\title{
Cultura dos links: conjunção e conexão nas redes
}

\section{RESUMO}

Este artigo discute a cultura dos links ativa na Internet com as práticas de trocas entre blogs, sites pessoais, listas de discussão entre outras. Uma comunicação em rede, que apesar das possibilidades que o dispositivo tecnológico proporciona, acaba se restringindo às atividades de conexão em detrimento da conjunção e do coletivo, produzindo uma cultura autocentrada, passiva e sem confrontos.

\section{PALAVRAS-CHAVE}

- redes

- comunicações

- blogs

\section{ABSTRACT}

This paper discusses the culture of links active in the internet with the exchange practices between weblogs, personal sites and discussion lists among others. A network communication which, albeit the possibilities provided by the technological device, is restrained to connection activities in detriment of conjunction and collectiveness, thus producing a self-centered, passive and confrontationless culture.

\section{KEY WORDS}

- networks

- communication

- weblogs
A Internet tornou-se 0 cenário de várias forças transformadoras da sociedade, como o movimento copyleft, no início da década de 90, a explosão das mídias táticas, o aparecimento de uma cultura de troca e exposição formada por blogs, fotologs, comunidades e listas de discussão, atravessada por uma ideologia P2P. Estes são exemplos do modelo de comunicação horizontal, retroalimentável, plural que passa a marcar a ascensão de novas reflexões sobre a cultura quando imagens, músicas, palavras e idéias se desatrelam de seus suportes materiais tradicionais e passam a correr o planeta.

Uma cultura que tem como característica principal, além do uso da Internet, atuar conforme o modelo da Rede - a forma emergente de organização da pós-modernidade. As ferramentas básicas de participação passam a ser o e-mail, os programas de buscas, os blogs e webcams que criam novas formas de elaboração e de publicização trazendo uma ruptura entre o público e o privado. Uma comunidade de cooperação abstrata em que os lugares da produção e do consumo estão presentes uns para os outros, independentemente da localização geográfica em que a rede é o lugar da produção, da circulação e da reprodução.

É a comunidade que produz e, ao produzir, é reproduzida e redefinida. Ela também é cada vez mais móvel pelos aparatos de comunicação nômade como palms, celulares, PCs de bolso. Com a mobilidade surgem temas como autoria, plágio, hackeativismo, copyright, copyleft, sample, mix que envolvem compartilhamento, cooperação e descentralização. Este cenário propõe novos desafios para a relação entre indivíduo e coletividade (cf: Pinheiro e Silva, 2005).

O paradigma das redes ocupa lugar central no pensamento contemporâneo: na vida, na comunicação, na sociedade, na política, na economia e nas ciências. Do mercado financeiro ao código genético, dos ativistas de Seattle aos ataques terroristas, da Internet ao sistema de transportes, compreender o funcionamento das redes torna-se o ponto comum das mais diversas áreas de conhecimento. O campo da comunicação, hoje atravessado pelas tecnologias de redes de informação e de distribuição, também se depara com questões que envolvem decisões e escolhas em relação ao estabelecimento de limites do controle e do acesso à Internet, dos valores de distribuição e circulação em rede de informação, da amplitude dos conhecimentos e saberes que constituem uma cultura do link. Talvez possamos resumir que a atividade de comunicação se transforma e passa a privilegiar não mais a conjunção e sim a conexão (cf: Berardi). ${ }^{1}$ Como essa mudança altera os processos de subjetivação quando mediados por dispositivos

\section{Marta de Araújo Pinheiro ECO/UFRJ}


que promovem formações culturais, práticas de poder e modos de comunicar entrelaçados através de links ilimitados sob a forma de redes?

\section{A comunicação em redes: conexão e conjunção}

Apoiados na distinção feita por Berardi (2005), apresentamos duas modalidades de comunicação em rede. A primeira seria a conexão que implica a funcionalidade de materiais conectados, um modelo funcional que predispõe à interface em que cada elemento permanece distinto e funcionalmente interativo. A segunda seria a comunicação que busca a conjunção, pois procura o outro num jogo contínuo entre elementos díspares e promove encontros e fusões imprecisos, imperfeitos, sem repetição, mas contínuos através de formas e formatos irregulares. Já a conexão, seria sempre pontual e repetível na interação entre funções que seguem uma compatibilidade entre partes de acordo com certo padrão já prédeterminado.

Ao mesmo tempo em que as tecnologias de comunicação e informação (TCI) promovem a descentralização e a não linearidade dos processos comunicativos, prometendo uma comunicação abrangente, fluida e global, podem trazer também consigo a efemeridade, o ocultamento dos antagonismos e dos conflitos, que correspondem a uma subjetividade enclausurada e ansiosa, cansada de estímulos, apática e desprovida de compartilhamentos que impedem a abertura a novos modos de ser e agir. Como romper o automatismo da conexão, já que ela é só uma das possibilidades entre as modulações que a conjunção permite?

Hoje a proliferação dos meios chega a ser ilimitada, em que fazer a escolha, um caminho na profusão das redes, compreende fabricação, simulação, partilha e experimentação, e isto ocorre ao mesmo tempo em que a indústria tende a miniaturizar os equipamentos de modo a individualizar as demandas, privatizar as atividades e privilegiar a conexão como modelo de comunicação. A tensão entre conjunção e conexão é mantida através de dispositivos tecnológicos em rede com seus modos de apropriação, comunicação e produção de sentido.

As redes são construídas por um contínuo de relações governadas por interesses, gostos, afinidades, afetos e pragmatismo. Nelas, as relações são móveis e determinam o poder como também o produzem, assim como operam em um diagrama com escalas, atravessando redes locais para ações mais complexas. Trata-se de uma escolha política pensar a comunicação em rede como conjunção porque esta escolha implica destacar a diversidade e o conflito, não a unidade ou a comunidade harmônica, apesar da indiferença que é proporcionada no contato entre os pontos nas redes.

Uma cultura da seleção e da determinação do link constitui um novo campo do político hoje, rompendo com a suposição de que tudo conecta com tudo, fato que não é devido à impossibilidade técnica ou à falta de espaço.

Como representantes desta cultura da conexão, as práticas de trocas de arquivos, mensagens, impressões na criação de blogs materializam e definem uma ideologia da troca e do link. Como diz o Le Monde (2006), “... nos fins dos anos 90, era necessário ter um e-mail, no começo dos anos 2000 era de bom tom ter um site pessoal. Agora, é necessário ter criado seu blog. É o último lugar virtual da moda". O blog é um página na web pessoal, um diário ao mesmo tempo íntimo e público. Composto essencialmente de anotações que aparecem em ordem cronológica das mais recentes às mais antigas, podendo ser comentadas pelos leitores e enriquecidas de links externos, acrescidas de podcasts, áudio e vídeo.

\section{"a conectividade é uma qualidade e não um estado ou coisa; ela pode ser baixa, alta, estreita, larga, etc."}

Os blogs são capazes de combinar propostas individuais, exprimir paixões do cotidiano, estabelecer um debate político ou cultural, criar redes de interesse, de difusão e circulação. Eles são espelhos das subjetividades contemporâneas conectadas, motores de inovações dos dispositivos comunicacionais, técnicos e científicos (trocas automáticas de fotos, artigos, links, etc.). Entretanto, a cultura do blog tem promovido zonas fechadas de afinidade, apesar da articulação aparentemente sem fim das "linkagens", pois o que não agrada está sempre fora, fechado às trocas. Esta prática estabelece uma rede incestuosa de auto-reprodução com a recusa dos antagonismos e das diferenças que não deixa reverberar a tensão entre espaços de comunicação abertos e fechados, entre a conjunção e a conexão nas redes e o oferecimento de links.

Ao mesmo tempo em que isto ocorre, assistimos batalhas sobre o controle da distribuição da cultura, das informações e dos saberes que são sintomas da expansão crescente da conexão planetária promovida pelas tecnologias da informação e comunicação. O que a prática da conexão traz como modificação? Seria uma anarquia cultural em nome da qual dispositivos de controle devem ser acionados? Como escapar das conexões que produzem o recentramento de uma cultura sem antagonismos e promovem uma troca consensual e amena? Como politizar esta cultura e sob que regime de valores? Como criar vínculos a partir dos vácuos deixados por uma comunicação que privilegia a conexão?

Como os fluxos poderiam produzir uma amplitude de escala que não seria simplesmente a ligação ao que já é padrão, mesmo que aparentemente este 
padrão pareça ilimitado, e para daí submergir na repetição infinita? A frase de Bataille, "a busca angustiada de uma expressão no limite do impossível", pode ser transposta para o padrão da comunicação digital, diante do consumo e reprodução em escala massiva porque, paralelamente ao automatismo das conexões, um capital imaterial é constantemente doado nos processos comunicativos via redes informacionais, nas quais milhões de pessoas criam, compõem, copiam e distribuem milhares de arquivos. Valores como liberdade, autonomia, circulação convivem com questões de acesso, privacidade, domínio.

\section{As redes como modelo}

Antigas ideologias, anarquia e oligarquia, parecem retornar no mundo das TCI quando verificamos a guerra entre distribuição e concentração de informação. Anarquia é um sistema de governo sem autoridade, já a oligarquia governa pela e para a autoridade. Esta última se justifica pelo pânico de um possível mundo anárquico. E a anarquia se justifica como reação à oligarquia, de modo que só faz reproduzir alternativas ressentidas e vazias de propostas.

A palavra grega anarchos significa "sem autoridade" ou "negação da lei", gerando assim a interpretação de que a propriedade é uma tirania. Por sua vez, a oligarquia promove bloqueios e interdições em nome da preservação da propriedade e do status hierárquico (Vaidhyanathan: 2004). O modelo de rede oligopolista é caracterizado pelos sistemas de difusão, em que existe um ponto único e relativamente fixo de emissão e os pontos de recepção soam potencialmente infinitos e territorialmente indefinidos: um número relativamente pequeno de empresas, por exemplo, pode dominar todas as redes. O modelo de rede anárquica é a conexão de nós e links aleatoriamente distribuídos, em que a organização se dá a partir da sua auto-organização. As redes da nova infra-estrutura de informação são um pouco híbridos dos dois modelos. As redes trazem com elas o sonho da democracia plena onde tudo se conecta e qualquer um pode ser o nó em algum momento, seja na emissão ou na recepção. Poderíamos dizer que elas propõem uma anarquia com governabilidade através da colaboração, deliberação, consenso e práticas mútuas de ajuda.

As redes de informação e comunicação também são um dispositivo cognitivo, ético e criativo. Aprender uma nova linguagem de comunicação é também dominar um pequeno arsenal de ferramentas de software junto com ela (Johnson: 2005, p.92). A internet desafia nossas mentes de três maneiras: ser participativa; forçar os usuários a aprenderem novas interfaces; e criar novos canais para a interação social (ibidem: p. 93). O Google é hoje o principal meio em termos de conhecimento sobre a nossa própria cultura. Acessá-lo é participar dos agenciamentos coletivos da nossa atualidade.
As ciências da rede buscam encontrar princípios comuns em fenômenos diversos: uma teia coletiva e conectada, tanto na vida, na matéria, na economia e na sociedade. Mas o que entendemos por coletivo e conectividade? A coletividade é uma agregação de unidades individuais cujas relações são especificadas no contexto que pressupõe organização espacial, o que não quer dizer proximidade espacial, pois pode agregar de modo disperso, sem um grupo centralizado (Thacker: 2004). Mas o que mantém a coletividade coesa, isto é, em conjunção?

\section{"a produção hoje abrange cada aspecto da vida, transformando qualquer atividade e todo recurso em uma mercadoria avaliada, privatizada e valorizada"}

A conectividade é uma qualidade e não um estado ou coisa; ela pode ser baixa, alta, estreita, larga, etc. Ela não é sinônimo de relação, mas a supõe: é um termo comum que torna a relação possível. Concepção enganosa é que a conectividade imediatamente implicaria coletividade e conjunção, assim como também supor que a mera existência de pontos de conjunção conduziria à emergência de formas políticas novas, de uma democracia mais direta ou imediata, de uma cultura mais inclusiva e aberta (ibidem).

As redes são exemplos de mutações estruturalmente inovadoras, mas politicamente ambivalentes. Elas podem dispor movimentos antiglobalização e fluxos globais do mercado financeiro, ajudas humanitárias e atos terroristas, o autocentramento narcisista dos blogs ou a sua transformação em pontos de conjunção e compartilhamento. Como modelo tecnológico descentralizado, a rede não significa imediatamente democratização da informação e liberalização. O acontecimento de Seattle implicou, por exemplo, a junção de dois dispositivos: um imaterial, a criação de um grupo de afinidades, e um técnico, o uso de tecnologias móveis e de rede.

Neste sentido, a rede como padrão global surge de interações locais, forma um todo que não pode ser deduzido da análise de partes individuais. É na tensão entre coletividade e conectividade que fenômenos de grupos se tornam políticos (ibidem).

\section{Pólos, nós e links}

Na ciência da rede, encontramos a tomada do espaço como um ponto inicial. Há um padrão comum de organização identificado como rede nos sistemas vivos, que começou na década de 20 , quando estuda- 
ram as teias alimentares e, após isto, o modelo de rede foi estendido a todos os níveis sistêmicos: do cérebro ao ecossistema, da célula ao tecido social. A rede possui certas propriedades, entre elas, a nãolinearidade, pois ela se estende em todas as direções: uma mensagem pode percorrer um longo percurso e poderá se tornar um laço de retroalimentação. Outra propriedade é a capacidade de regular a si mesma, a auto-regulação. Esta última possibilita uma terceira, a emergência de novas estruturas e formas de comportamento em sistemas abertos e afastados do equilíbrio, construídas por laços de retroalimentação. (Capra: 1996). As redes passam a ser concebidas pela auto-organização, entendida como emergência de um modelo global a partir de interações locais: uma intencionalidade sem intenção, um ato sem ator e um todo heterogêneo.

Contudo, este paradigma da rede é inábil para dar conta dos componentes do tempo, da duração e da mudança dinâmica, que precisam ser pensados nas redes vivas, o que obriga a questionar a separação entre nós e links, a natureza da causalidade, a qualidade mensurável das redes e a priorização dos nós sobre os links ou linhas.

Como constata Vaidyanathan (2004), se a coletividade é mais que a soma de números, então sua intencionalidade é o que a qualifica. E se a conectividade é mais que uma conexão aleatória, então é o padrão que qualifica a conectividade. Redes, então, são formas de organização distribuídas que facilitam a coletividade, qualificada pelo seu propósito e padrão. Redes podem formar uma coletividade pela conectividade, enquanto os movimentos nas redes podem iniciar uma conectividade, mas somente através da coletividade.

As redes foram concebidas como uma quantidade relativamente pequena de nós conectados a muitos outros pontos. As redes contêm nós destacados que são os pólos de convergência e irradiação, nomeadas como "redes aleatórias", o que significa que certos pólos têm uma quantidade aparentemente ilimitada de links e nenhum nó se parece com os demais. Por quarenta anos, a ciência tratou todas as redes complexas como sendo completamente aleatórias. A teoria de redes aleatórias diz que, apesar da localização randômica dos links, o sistema resultante será profundamente democrático: a maioria dos nós terá aproximadamente a mesma quantidade de conexões. Esta teoria traz uma visão espacializada das redes.

Será a Internet uma rede aleatória? As pessoas seguem seus próprios interesses para decidir a que páginas elas irão vincular seus documentos e, devido à diversidade de interesses e enorme quantidade de páginas entre as quais é possível escolher, o padrão de conexões resultante deveria parecer razoavelmente aleatório. Mas se poderia deduzir deste padrão o caráter democrático e conjuntivo das redes? Em um mapeamento realizado pelo Centro de
Pesquisa de Redes Complexas, coordenado pelo físico Albert-László Barabási, o resultado revelou um número reduzido de páginas extremamente conectadas que mantêm a coesão da Internet. Mais de $80 \%$ das páginas no mapa possuíam menos de quatro links, e uma pequena minoria, menos de 0,01\% de todos os nós, tinha mais de mil links. Ainda revelou que um só documento era referenciado em mais de dois milhões de outras páginas. Na verdade, a Internet seria uma "rede sem escala", na denominação de Barabási (2003).

\section{"uma experiência cultural, política e tecnológica interessante tem estimulado um exercício de autoprogramação e automediação culturais"}

Mas a que se deve tal distribuição em pólos concentrados? Graças à natureza crescente das redes reais, os nós mais antigos tiveram maiores oportunidades para adquirir links. É um processo de vinculação preferencial: os mais conectados são mais procurados. Daí decorre uma grande concentração em certos pólos: nós com grande quantidade de links. Dois mecanismos estão aí implicados: crescimento e vinculação preferencial ajudam a explicar a existência de pólos de convergência e irradiação. Espacialização e intensidade constituem uma topologia que implica escolhas e opções não aleatórias, portanto, trata-se da formação de um "espaço qualitativo". Isso nos leva a concluir que a democratização potencial das redes não é determinada só pela sua natureza tecnológica, quer dizer, trata-se também de uma tarefa política de construção e transformação cultural.

Para Negri (2003, p.232), a rede torna-se uma rede de comunicação quando se formam valores cooperativos em sentido pleno, seja produtivo, seja político. Haveria uma isomorfia da rede no real e no ideal? Para o autor, o poder da rede e a guerra da rede modificam a realidade social e, ao mesmo tempo, correspondem a novas condições e modalidades do pensamento (ibidem, p.248-249). As redes potencialmente podem ser pensadas como aberturas na comunicação social, atuando contra os valores e os sistemas que fecham a experiência e a linguagem na repetição, empurrando para um esvaziamento do sentido sedimentado.

\section{Política, cultura e comunicação em redes}

Michel Foucault compreende as tecnologias como dispositivos que promovem processos de subjetivação e invenção de possibilidades de vida. Hoje assis- 
timos à convergência da vida e da política, às subjetividades ligadas aos automatismos tecnobiológicos e tecnocognitivos, e à produção do imaginário pela mídia. Seguindo a formulação de Foucault, o sujeito não preexiste à história, ao processo social, às formações de poder e aos dispositivos que modelam a vida. Neste sentido, a política hoje é reconceitualizada na sua ligação à cultura como produção de valores e sentidos, na interface do relacionamento com o universo tecnomidiático.

A produção hoje abrange cada aspecto da vida, transformando qualquer atividade e todo recurso em uma mercadoria avaliada, privatizada e valorizada. Como liberar as conexões, criar suspensão e promover conjunções? Talvez signifique não apenas se conectar, se informar, mas também participar ativamente na elaboração do acontecimento. À produção centralizada, racionalizada, espetacular, corresponde outra produção, qualificada na utilização.

Na perspectiva da enunciação, Michel de Certeau (1999) fala-nos de uma apropriação ou uma reapropriação da língua pelos locutores, prática significativa porque instaura um presente relativo a um momento ou a um lugar a partir de um contato com o outro numa rede de lugares e relações. Trata-se de uma astúcia, uma marginalidade que não é mais só de pequenos grupos, mas de muitos. Esta astúcia, que produz um vácuo de sentido, parte de uma ação de pleno pertencimento e, por isso, não se trata de estratégias (gerência de relacionamentos e de conexões nas redes, por exemplo), mas de táticas. Certeau faz uma distinção entre estratégia e tática útil na questão da interação nas e das redes comunicacionais. A estratégia é um cálculo de forças que se supõe estar em um lugar isolável. Já a tática é um cálculo que não considera a existência de uma fronteira distinguindo o outro. Por conseguinte, só tem como lugar o outro e é nele que se insinua, fragmentariamente. Por não possuir uma base onde capitalizar os seus ganhos, armar suas expansões e assegurar uma independência em face das circunstâncias, quer dizer, por estar num não-lugar, a tática depende dos acontecimentos para transformá-los em oportunidades. A tática aproveita a ocasião e é uma performance operacional que depende dos combates e dos prazeres cotidianos.

As estratégias, segundo Certeau, escondem a sua relação com o poder sob cálculos objetivos, guardados em lugares próprios e instituídos. Já a tática se dá através de práticas cotidianas que produzem sem capitalizar, em que a atividade substitui a passividade, "o conversar e o tagarelar" como criações de comunicação que não pertencem a ninguém. Uma rede de efeito provisório e coletivo de competências na arte de manipular "lugares comuns" e jogar com o inevitável dos acontecimentos para torná-los "habitáveis", inventando-se linguagens, modos de estar juntos e de atuação em redes.

Ainda que se reconheça o papel relativamente independente dos usuários e participantes das redes, não se pode esquecer sua posição subordinada. Uma comunicação que ultrapasse as limitações da pura conectividade é pensada às vezes como se tratasse unicamente de anular a distância, ao criar condições para que todos tenham acesso aos bens, à informação, não só materialmente, mas também a um quadro de formação e educação. Sendo concebida apenas dessa maneira, a comunicação em rede corre o risco de tornar-se autoritária.

Devemos considerar que a democracia é pluralidade, o que implica polissemia de interpretação e uso (cf: Canclini, 1997). Contudo, de nada adianta cairmos num relativismo que admite a legitimidade das diferenças e pronto. Não basta socializar os "bens legítimos". Pode-se problematizar o que deve se entender por legítimo, o seu valor e quem o legitima, num jogo de valorização e desvalorização. Na verdade, o mais interessante talvez seja não apenas socializar o que já aí está, mas distribuir o excesso, criando condições para que tanto as formas instituídas como as marginais e heterodoxas se manifestem e se comuniquem. O terminal relacional faz da subjetividade uma questão coletiva, indissociável das conversações e narrativas que acompanham o desenrolar dos acontecimentos.

\section{"o espaço da rede não é naturalmente aleatório e, por isso, necessariamente mais democrático e ativo"}

Neste sentido há uma requisição cultural. Como promover nas "redes sem escalas" a difusão e a distribuição da inteligência por meio de trocas associadas às maneiras plurais de sentir e de ser, e que optem por uma conjunção cooperativa capaz de confrontar tanto a indiferença, a vacuidade e o fechamento que a comunicação em rede pode se tornar?

\section{Os blogs e a cultura de link}

Uma experiência cultural, política e tecnológica interessante tem estimulado um exercício de autoprogramação e automediação culturais: os blogs, com suas tecnologias paralelas (syndication, videoblogging, fotolog, podcasting) e sua estética de bricolage (sampling, mix, customização) provocam uma reapropriação da comunicação que indica um forte fator relacional na cultura de rede. ${ }^{2}$

Graças aos protocolos de sindicação de conteúdos, os novos blogs ultrapassam o seu autocentramento e aparecem sob a forma de textos, de links de hipertextos, imagens, fotos, que possibilitam a inserção de comentários conectados. Sindicação (syndication) é o ato de agregar ou colher informações a respeito de algo, compartilhando-as por diversos 
meios de comunicação através do RSS (Really Simple Syndication), forma padronizada de distribuir pela Internet que permite um blog receber automaticamente todas as atualizações.

Este dispositivo possibilita a informação circular de modo autônomo nas redes, seguindo os mecanismos de fluxo que vão além da publicação em um site, para se difundir de modo mais aleatório e abrangente, emancipando os conteúdos do site de origem para outros, o que torna a informação mais expandida. Este é um procedimento em que o blogueiro torna disponível o todo ou as partes de seu conteúdo para publicação em outro site gratuitamente para construir agregações de crônicas, mensagens, fotos, vídeos, etc. Graças ao RSS, que cria fios de sindicação e permite uma convergência social de conteúdos, estabelece-se uma dinâmica polifônica da subjetivação plural de gostos e interesses a partir de um processo de conjunção coletiva.

O uso interativo da informação, da comunicação e da cultura constrói um conjunto de micro-atividades inseridas em redes que habilitam formas sociais e culturais emergentes, precárias e vulneráveis, associadas aos modos de colaboração temporária e voluntária. Neste contexto, são exploradas as múltiplas virtualidades da comunicação conjugadas que a cultura dos links oferece e que podem ir além do automatismo dos atos de conexão. Ao promover uma cultura de links ampliada, estes blogs, associados aos novos procedimentos de vinculação, permitem práticas entrelaçadas de saberes, interesses e afetos que passam a considerar as escolhas e seleções, em confronto ou em consenso, com as dos outros, o que permite dizer que o espaço da rede não é naturalmente aleatório e, por isso, necessariamente mais democrático e ativo. Esta aleatoriedade também pode implicar em hierarquizações e fechamentos, em "redes sem escala", portanto, comunicar nas redes também requer que se pense e se politize esta "cultura dos links". mfamecos

\section{NOTAS}

1. A conceituação e a distinção entre conexão e conjunção são apresentadas por Franco Berardi.

2. Sobre blogs e sindicação, remeto ao artigo de Aris Papathéodorou indicado nas referências.

\section{REFERÊNCIAS}

BARABÁSI, Albert-Lászlo. Linked. New York: Penguin, 2003.

BERARDI, Franco. Biopolitics and connective mutation. Disponível em:

http://culturemachine.tees.ac.uk/, 2005.
BLOGSFHÈRE, modes d'emploi. Le monde.

Disponível em: Le monde fr. 11/01/2006

CANCLINI, Nestor Garcia. Culturas híbridas. São Paulo: Edusp, 1997.

CAPRA, Fritjof. A teia da vida. São Paulo: Cultrix, 1996.

CERTEAU, Michel de. A invenção do cotidiano. $4^{\mathrm{a}}$ ed. Petrópolis: Vozes, 1999

JOHNSON, Steven. Surpreendente. São Paulo: Elsevier, 2005.

NEGRI, Antonio. Cinco lições sobre o império. Rio de Janeiro: DP\&A, 2003.

PAPATHĖODROU, Aris. Syndication, information nomade et medias intimes. In: Multitudes. $\mathrm{n}^{\circ}$ 21, été, 2005.

PINHEIRO, Marta de Araújo; SILVA, Daniel de Lima. Internet e comunicação de resistência. In: Comum. v. 11 - no 25 - julho/dezembro 2005 - Rio de Janeiro. p. 166-176.

THACKER, Eugene. Networks, swarms, multitudes. Disponível em: http://www.ctheory.net/, 2004.

VAIDHYNATHAN, Siva. The anarchist in the library. New York: Basic Books, 2004. 